\title{
PERENGKAHAN PRODUK CAIR BATUBARA DENGAN KATALIS Ni/ZEOLIT
}

\author{
Linda Suyati ${ }^{1}$, Bambang Setiajii ${ }^{2}$ dan Triyono ${ }^{2}$ \\ ${ }^{1)}$ Laboratorium Kimia Fisik Jurusan Kimia FMIPA UNDIP, Semarang \\ ${ }^{2)}$ Laboratorium Kimia Fisik Jurusan Kimia FMIPA UGM,Yogyakarta
}

\begin{abstract}
ABSTRAK
Penelitian pirolisis tir batubara dilakukan dengan menggunakan metode alir termokopel dalam reactor. Temperatur reaktor konstan pada temperature $450^{\circ} \mathrm{C}-700^{\circ} \mathrm{C}$ untuk reaksi termal. Dan untuk reaksi katalitik dilakukan pada temperature $350^{\circ} \mathrm{C}-600^{\circ} \mathrm{C}$. Berat katalis dan laju alir $\mathrm{H}_{2}$ adalah konstan.

Hasil menunjukkan bahwa pada temperature tinggi reaksi termal pirolisis adalah gas, sedangkan dengan menggunakan katalis adalah kokas. Konversi dengan katalis Ni/Zeolit dibawah temperature $550^{\circ} \mathrm{C}$ lebih besar dibandingkan secara termal. Hasil cairan terbanyak pada temperatur $600^{\circ} \mathrm{C}$ hasil utama senyawa phenol pada reaksi katalitik.
\end{abstract}

Kata kunci: Pirolosis, katalis dan konversi

\section{ABSTRACT}

This research of coal tar pyrolysis was carried out using flow method completed by a thermocouple in reactor. The temperature of reactor was constanted at $450^{\circ} \mathrm{C}-700^{\circ} \mathrm{C}$ for thermal reaction, and $350^{\circ} \mathrm{C}-600^{\circ} \mathrm{C}$ for catalytic reaction. The weight of catalyst and flow rate of $\mathrm{H}_{2}$ was constanted.

The experiment result showed that at higher temperature of thermal pyrolysis reaction produced more gas, but using Ni/Zeolite catalyst produced more coke. Conversion by the Ni/Zeolite at temperature below $550^{\circ} \mathrm{C}$ was greater than thermal reaction. Catalytic result was greater at temperature $600 \mathrm{C}$ with compound phenol.

Key words: Pyrolysis, catalyst and conversion

\section{PENDAHULUAN}

Indonesia mempunyai cadangan batubara cukup besar kurang lebih 32 milyar ton. Sebanyak $71 \%$ terdapat di pulau Sumatra dan $27 \%$ di Kalimantan sisanya di pulau Jawa, Sulawesi dan Irian Jaya (Komarudin, 1992). Batubara tersebut sebagian besar digunakan masyarakat sebagai bahan bakar secara langsung dalam bentuk briket yaitu bahan bakar padat dengan bentuk dan ukuran tertentu yang terdiri dari partikelpartikel batubara halus dan bahan pengikat disamping sebagai pembangkit tenaga listrik.

Pembakaran langsung batubara tersebut banyak efek negatifnya, karena kurang aman bagi lingkungan, oleh karena itu perlu dikembangkan usaha-usaha melalui penelitian untuk meningkatkan nilai guna dan nilai ekonomis yang tinggi dengan jalan mengolah batubara menjadi bahan yang mudah dalam pengangkutan, mudah dalam penggunaannya dan aman bagi lingkungannya.

Salah satu cara untuk mendapatkan batubara yang diinginkan adalah dengan pirolisis yaitu thermal cracking tanpa adanya oksigen (Anderson, tanpa tahun). Hasil utama dari pirolisis adalah gas, cairan (tir batubara) dan residu (arang). Tir batubara berwarna hitam kecoklat-coklatan dan pada suhu kamar kental. Berat molekul rerata tir batubara antara 200 sampai 1200 terdiri dari hidrokarbon rantai panjang, oleh karena itu perlu dipecah lagi menjadi rantai yang lebih pendek untuk mendapatkan senyawa karbon fasa cair dengan fraksi yang lebih ringan (Rokhati, 1999).

Menurut Vigouroux (2001), produk pirolisis berupa senyawa-senyawa dengan rantai yang 
bervariasi. Pemecahan rantai panjang produk pirolisis menjadi rantai yang lebih pendek dapat dilakukan melaui proses perengkahan katalitik.

Zeolit merupakan katalis yang baik,karena mempunyai pori atau saluran yang besar dan memiliki luas permukaan besar serta tingkat keasaman yang cukup tinggi (Anderson, tanpa tahun). Dalam industri pengolahan minyak bumi dan petrokimia, zeolit digunakan sebagai katalis asam dalam perengkahan. Mengingat zeolit alam sangat melimpah dan murah, maka penggunaannya sebagai katalis dapat menurunkan biaya produksi (Vigouroux, 2001).

Zeolit memiliki ukuran pori tertentu yang selektif pada proses katalitik. Pori berperan dalam modifikasi molekul. Molekul yang melebihi ukuran pori akan mengalami perengkahan. Molekul hidrokarbon yang dapat melalui pori zeolit berkisar antara $C_{5}$ sampai $C_{10}$ (Hamdan, 1992).

Penelitian yang dilakukan oleh Rokhati (1999) dengan memakai katalis zeolit yang tadinya reaksi berlangsung pada temperatur tinggi tetapi dengan katalis proses reaksi bisa berlangsung pada temperatur yang lebih rendah. Dalam penelitian ini dipakai katalis nikel yang diembankan pada zeolit.

Logam nikel Ni merupakan salah satu unsur transisi yang memiliki daya adsorpsi yang kuat. Hal ini disebabkan adanya karakterisasi orbital 3d yang memiliki elektro tidak berpasangan sehingga Ni cenderung berikatan dengan atom lain (King, 1982). Hal ini Ni dapat berperan sebagai katalis. Pada logam Ni akan terjadi proses adsorpsi molekul reaktan pada permukaan padatan logam yang memiliki elektron tidak berpasangan dalam orbital $3 \mathrm{~d}$ (Panchenkov, 1997).

Dalam penelitian ini, katalis Ni/Zeolit digunakan untuk perengkahan produk cair batubara dengan variasi temperatur dengan harapan diperoleh produk cair hasil perengkahan yang merupakan fraksi karbon ringan yang bermanfaat dengan kelimpahan yang lebih besar.

\section{METODE PENELITIAN}

Bahan yang direngkah adalah tir batubara bituminius yang berasal dari Kalimantan Timur dan dikerjakan di laboratorium Heat and Mass Tranfer (HMT) Pusat Antar Universitas Gajah Mada dengan jalan memanaskan batubara sebanyak kurang lebih $6 \mathrm{~kg}$ mulai dari temperatur kamar sampai dengan tempetur $1000^{\circ} \mathrm{C}$ dengan kecepatan kenaikan suhu $2^{\circ} \mathrm{C}$ permenit di dalam reaktor batch. Katalis $\mathrm{Ni} /$ Zeolit yang dipergunakan untuk perengkahan memiliki karakter: 5,40 mmol/g (standar amoniak), Luas permukaan $76 \mathrm{~m}^{2} / \mathrm{g}$.

Pirolisis dilakukan memakai reaktor alir dengan mengatur laju alirnya. Tir dimasukkan ke dalam wadah di dalam kolom reaktor yang telah diisi katalis dengan berat tertentu Kolom reaktor kemudian dimasukkan ke dalam tanur. Tanur dipanaskan sampai dengan temperatur tertentu, umpan dan gas dialirkan bersama-sama dengan kecepatan konstan. Tir teruapkan dan terpirolisis sepanjang reaktor. Hasil yang berupa cairan, padatan dan sisa hasil reaksi ditimbang, kemudian yang berupa cairan dianalis secara kualitatif memakai instrumen GC-MS.

\section{HASIL DAN PEMBAHASAN}

Hasil pirolisis tir batubara disajikan pada tabel 1 dan tabel 2. Konversi cairan yang didapat dari 
reaksi termal kelihatan berkurang tajam setelah temperatur mencapai $600^{\circ} \mathrm{C}$, tetapi gas terbentuk pada temperatur diatas harga tersebut. Pemakaiam katalis dapat memperbanyak hasil cairan., tetapi tak menunjukkan penurunan yang terlalu tajam pada temperatur tersebut.

Hasil pembentukan kokas pada dasarnya partikel kecil hasil frahmentasi sehingga membentuk partikel yang lebih besar konstan pada pirolisis termal, sebab hasil reaksi bisa langsung keluar reaktor dengan bantuan gas $\mathrm{H}_{2}$, sehingga tumbukan antar partikel sangat kecil. Sebaliknya dengan katalis $\mathrm{Ni} /$ Zeolit, partikel teradsorpsi lebih dahulu di permukaan yang mengakibatkan penumbukaan pada partikel kecil, sehingga mudah mengalami polimerisasi (Rokhati, 1999).
Konversi mengalami peningkatan, baik secara termal maupun dengan menggunakan katalis $\mathrm{Ni} /$ Zeolit. Pada temperatur dibawah $600^{\circ} \mathrm{C}$, konversi katalitik menjadi lebih banyak, akan tetapi hal sebaliknya terjadi diatas temperatur tersebut, sebab reaksi termal memerlukan cukup banyak energi untuk dapat melewati energi aktivasi. Pemakaian katalis pada temperatur tinggi dapat memberikan hasil frahmentasi lebih banyak,akibat pengaruh temperatur, kokas lebih banyak terbentuk sehingga dapat menurunkan aktivitas katalis. Banyaknya konversi total reaksi (dalam \%) pada temperatur yang bervariasi disajikan pada gambar 1 .

Tabel 1. Hasil pirolisis secara termal

\begin{tabular}{|c|c|c|c|c|c|c|}
\hline $\mathbf{T}\left({ }^{\circ} \mathbf{C}\right)$ & Umpan $(\mathbf{g})$ & Cairan $(\mathbf{g})$ & Coke $(\mathbf{g})$ & Residu (g) & Gas yang tidak terdeteksi $(\mathbf{g})$ & Konversi (\%) \\
\hline 450 & 5,89 & 3,38 & 0,28 & 1,68 & 0,55 & 71,47 \\
\hline 500 & 5,85 & 3,39 & 0,29 & 1,51 & 0,66 & 74,08 \\
\hline 550 & 5,94 & 3,36 & 0,30 & 1,42 & 1,04 & 76,77 \\
\hline 600 & 5,80 & 3,42 & 0,30 & 0,91 & 1,19 & 83,74 \\
\hline 650 & 5,85 & 2,74 & 0,30 & 0,68 & 2,13 & 88,35 \\
\hline 700 & 5,89 & 2,06 & 0,32 & 0,41 & 3,10 & 93,02 \\
\hline
\end{tabular}

Tabel 2. Hasil pirolisis dengan menggunakan katalis Ni/Zeolit

\begin{tabular}{|l|l|l|l|l|l|l|l|l|l|}
\hline $\mathbf{T}\left({ }^{\circ} \mathbf{C}\right)$ & $\mathbf{B}(\mathbf{g})$ & $\mathbf{S}(\mathbf{g})$ & $\mathbf{U}(\mathbf{g})$ & $\mathbf{C}(\mathbf{g})$ & $\mathbf{K L}(\mathbf{g})$ & $\mathbf{K T}(\mathbf{g})$ & $\mathbf{R}(\mathbf{g})$ & $\mathbf{G}(\mathbf{g})$ & $\mathbf{K}(\mathbf{g})$ \\
\hline 350 & 5,05 & 5,11 & 5,98 & 3,83 & 0,06 & 0,13 & 1,89 & 0,003 & 68,42 \\
\hline 400 & 5,05 & 5,12 & 5,89 & 3,92 & 0,08 & 0,15 & 1,75 & 0,07 & 72,03 \\
\hline 450 & 5,05 & 5,18 & 5,98 & 4,11 & 0,12 & 0,25 & 1,53 & 0,10 & 74,00 \\
\hline 500 & 5,05 & 5,24 & 5,98 & 4,12 & 0,13 & 0,32 & 1,44 & 0,11 & 76,01 \\
\hline 550 & 5,05 & 5,29 & 5,94 & 4,14 & 0,13 & 0,37 & 1,30 & 0,13 & 78,02 \\
\hline 600 & 5,05 & 5,31 & 5,94 & 4,22 & 0,12 & 0,38 & 1,11 & 0,23 & 81,36 \\
\hline 650 & 5,05 & 5,32 & 5,98 & 3,92 & 0,12 & 0,39 & 0,90 & 0,72 & 84,89 \\
\hline
\end{tabular}

Keterangan tabel 2: $\mathrm{T}=$ Temperatur $\left({ }^{\circ} \mathrm{C}\right), \mathrm{B}=$ Berat katalis awal $(\mathrm{g}), \mathrm{S}=$ Berat katalis setelah reaksi $(\mathrm{g})$, $\mathrm{U}=$ Sampel tir awal $(\mathrm{g}), \mathrm{C}=$ Cairan hasil pirolisis $(\mathrm{g}), \mathrm{Kl}=$ Kokas diluar katalis, $\mathrm{KT}=$ Kokas total $(\mathrm{g})$, $\mathrm{R}=$ esidu (g), $\mathrm{G}=$ Gas yang tidak terdeteksi (g), $\mathrm{K}=$ Konversi $(\%)$ 


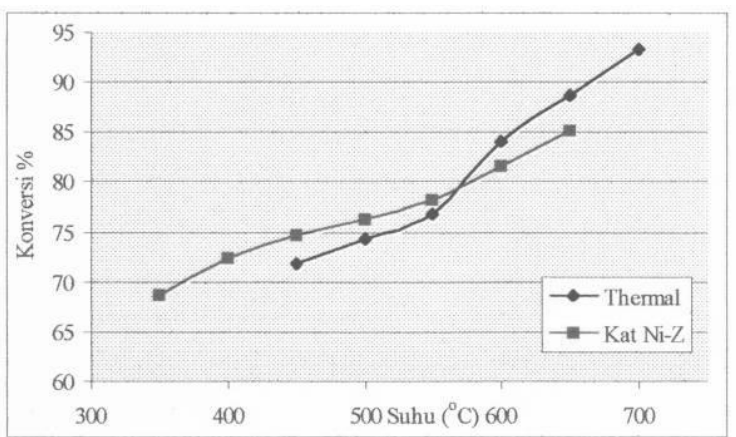

Gambar 1. Grafik konversi (\%) vs temperatur

Tir Batubara awal dan Cairan Hasil Pirolisis dengan Katalis Ni/Zeolit pada Temperatur $600^{\circ} \mathrm{C}$

Analisis kualitatif dilakukan dengan alat kromatografi gas jenis Shimadzu. Penggunaan katalis memberikan hasil perengkahan yang diungkapkan dengan pengurangan fraksi berat dari retensi 16,405 hingga 23,839 menit.Waktu retensi 4,919-10,10698 menit memperlihatkan adanya peningkatan produk. Kenaikan paling tajam sebanyak $8,66 \%$ deiperlihatkan oleh waktu 10,7 menit. Sebaliknya penurunan menjadi 3,32\% ditunjukkan oleh waktu retensi 16,405 menit.Terjadinya penambahan puncak bisa merupakan gabungan dari perengkahan maupun hasil polimerisasi. Kromatogram tir batubara awal dan cairan hasil pirolisis dengan menggunakan katalis Ni/Zeolit ditunjukkan pada gambar 2 dan 3 dan grafik \% konversi vs waktu retensi ditunjukkan dalam gambar 4 .

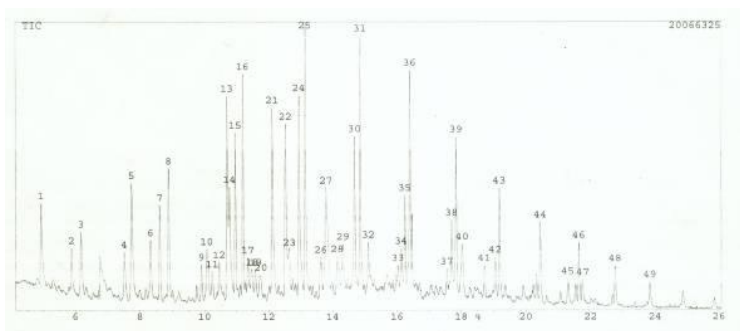

Gambar 2. Kromatogram tir awal

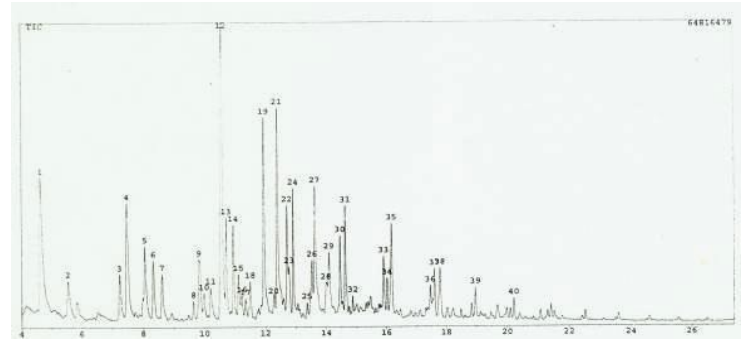

Gambar 3. Kromatogram Produk Cair Pirolisis dengan menggunakan Katalis Ni/ Zeolit Pada Temperatur $600^{\circ} \mathrm{C}$

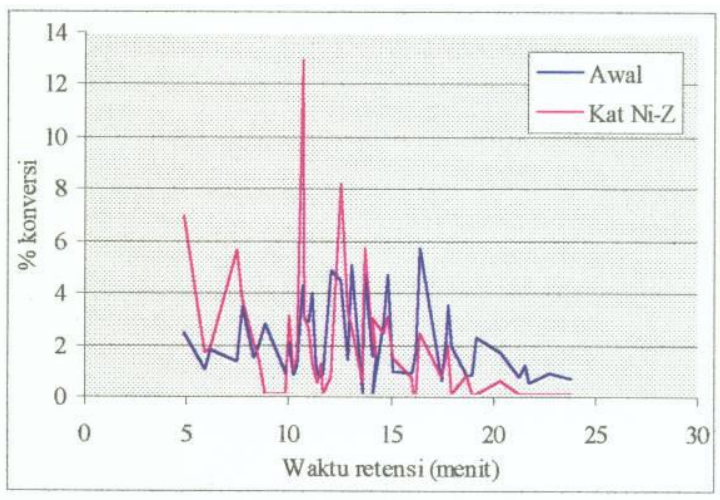

Gambar 4. Grafik Konversi (\%) vs waktu retensi (menit)

Tabel 3. Analisis GC-MS Produk Perengkahan dengan katalis Ni.Zeolit pada temperatur $600^{\circ} \mathrm{C}$

\begin{tabular}{|c|c|c|c|c|}
\hline $\begin{array}{c}\text { Puncak } \\
\text { No }\end{array}$ & $\begin{array}{c}\text { Waktu } \\
\text { Retensi } \\
\text { (menit) }\end{array}$ & $\begin{array}{c}\text { \%elimpahan } \\
\text { Kragmentasi }\end{array}$ & $\begin{array}{c}\text { Pola } \\
\text { Ferkiraan } \\
\text { Senyawa }\end{array}$ \\
\hline 1 & 4,617 & 6,97 & $91,65,39$ & Toulena \\
\hline 4 & 7,475 & 5,56 & $\begin{array}{c}106,91,77, \\
65,39\end{array}$ & $\begin{array}{c}1,2 \\
\text { dimetil } \\
\text { benzena }\end{array}$ \\
\hline 12 & 10,558 & 12,8 & $\begin{array}{c}94,74,66, \\
39\end{array}$ & Phenol \\
\hline 19 & 11,918 & 5,39 & $\begin{array}{c}108,77,51, \\
39\end{array}$ & $\begin{array}{c}\text { 3-metyl- } \\
\text { phenol }\end{array}$ \\
\hline 21 & 12,392 & 8,06 & $\begin{array}{c}107,77,51, \\
39\end{array}$ & $\begin{array}{c}\text { 4-metyl- } \\
\text { phenol }\end{array}$ \\
\hline 27 & 13,63 & 5,60 & $\begin{array}{c}122,107, \\
103,91,79, \\
65,51,39\end{array}$ & $\begin{array}{c}2,3- \\
\text { dimetyl } \\
\text { phenol }\end{array}$ \\
\hline 35 & 16,183 & 2,90 & $\begin{array}{c}85,71,57, \\
\text { Tridecana } \\
43\end{array}$ & . \\
\hline
\end{tabular}

Analisis kromatografi gas spektroskopi massa pada perengkahan cairan terbanyak $\left(600^{\circ} \mathrm{C}\right)$ dengan katalis Ni/Zeolit pada diperoleh hasil senyawa dengan kelimpahan yang paling utama phenol dan diikuti oleh turunan phenol. Hal ini disebabkan karena phenol tidak mudah 
terdegradasi akibat strukturnya yang sangat stabil.

\section{KESIMPULAN}

1. Konversi menggunakan katalis Ni/Zeolit memberikan hasil lebih banyak dibandingkan dengan konversi termal pada temperatur $350^{\circ} \mathrm{C}-550^{\circ} \mathrm{C}$, sedangkan pada temperatur diatas $550^{\circ} \mathrm{C}$ terjadi sebaliknya.

2. Kokas banyak terbentuk dengan menggunakan katalis Ni/Zeolit, sedangkan pada konversi termal banyak menghasilkan gas.

3. Hasil analisis dengan GC-MS senyawa yang terbentuk paling banyak adalah jenis phenol.

\section{DAFTAR PUSTAKA}

Anderson, J.R., and Boudart,M., Catalyst Science and Technology, Springler Verlag, Berlin.

Baheti, K, Nakbanpotes, W., and Phatip., 2000, Preconsentration of Gold by Rice Hush Ash, Journal of Minerals Engineering, Bangkok,
Hamdan, 1992, Introduction to Zeolites Synthesis, Characterization and Modification, $1^{\text {st }}$ edition, University Technology Malaysia, Kuala Lumpur,

King, D.A., 1982, The Chemical Physic of Solid Surface and Heterogeneous Catalysis, $1^{\text {st }}$ edition, Elsevier Publishing Company, Amsterdam

Komarudin, 1992, Bahan Bakar Dari Batubara Indonesia, Prospeknya di Tahun 2000-an dan Penguasaan Tehnologi, proseding Diskusi Ilmiah VII Hasil Penelitian LEMIGAS, Jakarta

Panchenkov, G.M, 1997, Chemical Kinetics and Catalyst, MIR Publishing, Moscow

Rokhati, N., 1999, Pirolisis Tir Batubara Secara Sinambung,Tesis S-2, UGM, Yogyakarta

Trisunaryati, W., Shiba, R., Miura, M., Nomura, M., Nishiyama, M., and Matukata, M., 1996, Characterization and Modification of Indonesian Natural Zeolite and Their Properties for Hidrocracking of Parafin, Journal of Japan Petroleum Instate, $\mathrm{Vol}$ 39, Japan

Vigouroux, R.Z, 2001, Pirolysis of Biomass, Dissertation, Royal Institute of Technology, Department of Chemical Engineering and Technology, Chemistry Technology, Stockholm 